\title{
Texas A\&M Law Review Fall 2020 Symposium: Containing Covid Catastrophes: Addressing The Effects Of Covid-19 On The Agricultural Industry Texas A\&M University School Of Law
}

James D. Bradbury

jim@bradburycounsel.com

Greg Ibach

Follow this and additional works at: https://scholarship.law.tamu.edu/lawreview

Part of the Agriculture Commons

\section{Recommended Citation}

James D. Bradbury \& Greg Ibach, Texas A\&M Law Review Fall 2020 Symposium: Containing Covid Catastrophes: Addressing The Effects Of Covid-19 On The Agricultural Industry Texas A\&M University School Of Law, 8 Tex. A\&M L. Rev. 661 (2021). Available at: https://doi.org/10.37419/LR.V8.I4.1

This Remarks is brought to you for free and open access by Texas A\&M Law Scholarship. It has been accepted for inclusion in Texas A\&M Law Review by an authorized editor of Texas A\&M Law Scholarship. For more information, please contact aretteen@law.tamu.edu. 


\title{
TEXAS A\&M LAW REVIEW FALL 2020 SYMPOSIUM
}

\section{CONTAINING COVID CATASTROPHES: ADDRESSING THE EFFECTS OF COVID-19 ON THE AGRICULTURAL INDUSTRY}

\section{TEXAS A\&M UNIVERSITY SCHOOL OF LAW Thursday, September 10, 2020, 3:15 pm}

\author{
PANELISTS \\ J im B radbury \\ G reg I bach
}

\section{INTRODUCTION}

PROFESSOR BRADBURY: Howdy! Welcome back from the break. My name is Jim Bradbury, I'm an adjunct law professor at Texas $A \& M$ and teach the $A$ griculture $L$ aw course. So it's a double pleasure that I get to join you today talking at this ag-law symposium on COVID. J ust a couple of words of thanks to our friends at D rake, as well as all of the students who've put this program together. For those of you who are attending, this entire program is put together by the students. So give a special thanks to them.

It's my honor today to introduce our next speaker, who is a very special guest to Texas $A \& M$ and Drake. It's $G$ reg Ibach who's the $U$ ndersecretary for $M$ arketing and R egulatory Programs for U SD A ${ }^{1}$ in W ashington, D.C. H e was confirmed by the U nited States Senate in 2017, and he's been serving since then, dealing with all of the policy issues that have arisen due to COVID and a whole variety of other issues that have been taking place in the last couple of years in agriculture. $\mathrm{H}$ is position's one of enormous responsibility; if you're not that familiar with USDA, his position is really the workhorse position in the senior administration at U SD A. They do both domestic and international marketing of our U.S. ag products. He has a responsibility over the ag marketing service, A nimal [and] Plant H ealth Inspection

D O I: https://doi.org/10.37419/L R .V 8.I 4.1

1. U SD A stands for the U .S. D epartment of A griculture, which provides "Ieadership on food, agriculture, natural resources, rural development, nutrition, and related issues based on public policy, the best available science, and effective management." See A bout the U.S. Department of A griculture, U.S. DEPT. AgRIC., https:// www.usda.gov/our-agency/about-usda [https://perma.cc/56X 5-567H ]. 
[Service], ${ }^{2}$ as well as grain inspection, then the Packers and Stockyards $\mathrm{A} \mathrm{ct}^{3}$ which is, in and of itself, an enormous job, as well as certain programs under the Farm Service A gency. ${ }^{4}$

$M$ r. I bach is a proud Nebraskan. B efore he joined the A dministration, he served as the D irector of the D epartment of A $g$ in N ebraska. While doing that, he also served as President of all of the state departments of agriculture- everyone in his position elected him to serve as president of that act.

I'm probably most pleased to report that he has a B.S. from U niversity of Nebraska with a background in animal science as well as ag economics. So, I'm always happy to see an ag-econ major do very well. So, thank you very much for joining us today here, Secretary Ibach, and I'll turn it over to you.

\section{DISCUSSION}

MR. IBACH: Thank you very much. It's my pleasure to be with you. $Y$ ou did a great job of kind of giving my background and experiences. O ne thing that you left out is I very much still consider myself a farmer and a rancher as well. My son, right now, is managing the day-to-day operations at our farm and ranch in central Nebraska. W e have a cow-calf and row-crop operation there, and in this administration, I was able to maintain my ownership interest in it. I just had to step away from day-to-day management and marketing decisions. A nd so I have a landing place at the end of my service to U SDA, if you will.

PROFESSOR BRADBURY : W ell, that's good. I still hope you get a chance to drive a tractor.

MR. IBA CH: Y eah. That's if my son will let me come back.

B OTH : *laughing*

M R. IBA CH : So anyway, but yes, I had the privilege to work as the D irector of A griculture in N ebraska- that's the equivalent of the secretary or commissioner of agriculture in other states, and some states

2. The A nimal and Plant Health Inspection Service ("A PHIS") is an arm of the USDA that focuses on a multitude of services, including animal health, imports and exports, and pests and diseases. See A nimal and Plant H ealth Inspection Service, U .S. DEPT. A GRIC., https://www.aphis.usda.gov/aphis/home/ [https://perma.cc/268D A TY B ].

3. 7 U .S.C.A. §§ 181-229c.

4. The Farm Service A gency serves "farmers, ranchers, and agricultural partners through the delivery of effective, efficient agricultural programs for all A mericans." History and Mission, U.S. Dept. Agric.: Farm Service Agency, https:// www.fsa.usda.gov/about-fsa/history-and-mission/index [https://perma.cC/D B 7CDKW 7]. 
it's called director - for about thirteen years, and before that, six years as the A ssistant D irector of A griculture. In my role there, I very much cooperated with the marketing and regulatory programs mission area because, in many cases, states are the local partner for U SDA to carry out those programs. So when I showed up here at U SDA, I was very familiar with A PHIS and A M S ${ }^{5}$ from those experiences. A nd it gave me a great opportunity on day one to be able to understand what my responsibilities here at U SD A were, as well as understanding it from a farmer perspective, as well as from a state agency director position what my expectations of the job from that viewpoint were here and what my expectations of the previous people that sat in my chair were. A nd so, I believe that that was a great experience to come into my role.

A s you mentioned, all plant and animal health-keeping pests and diseases that aren't in the U nited States out and trying to control and eradicate those that are in the $\mathrm{U}$ nited States-are my primary responsibilities there. B ut I also have biotech regulation under my purview, I have animal care, so animal-welfare programs, especially related to research animals, are under my jurisdiction, wildlife serviceswhether that be helping farmers control predatory animals, or protecting planes coming into and out of airports all around the world, especially in military installations from bird incurrences and things like that. On the A M S side, I have the hemp programs, I have the organic program, all the marketing orders and all the check-off programs, as well as grain grading, and fruit and vegetable grading, meat grading, and then looking at transportation systems, especially crop. So it is very diverse, and so it's interesting every day of the week, and so I appreciate that.

Today, I am charged with visiting with you about our response to COVID here at U SD A from a government-aid side of things. A nd I'm going to take that definition a little bit liberally, because I think some of the regulatory aid we gave during COVID was government aid. I also think we had food aid that we handed out. So I'm going to talk to you about our responses to the collapse of the food distribution system. I'm going to talk to you about the steps we took to feed hungry people as COVID evolved. I'm going to talk about USDA steps for food processing - especially the harvest of animals through COVID and the challenges that made themselves known. I'm going to then maybe talk more about the purer definition of aid-the implementation of the COVID-aid packages that Congress passed-and then maybe touch on some of the continuing ramifications that we see cur-

5. A M S stands for A gricultural Marketing Service, a USDA program that administers marketing services for various crops and performs various inspection-related functions. See A bout AMS: O ur Mission, U.S. DEPT. AgRIC., https:// www.ams.usda.gov/about-ams [https://perma.cc/Q BT 3-7Z34]. 
rently. A nd then I will make myself available for some question and answers and hopefully leave enough time for all of that.

A nd so, as we look at the collapse of the food distribution system immediately after the U nited States decided that COVID was a serious threat, and we asked people to stay home from work, and we started restricting travel, and the expectations of employees to be able to move around if they weren't essential personnel in essential industries (fortunately, or unfortunately, most of what I oversee were considered essential industries because they were involved in the food production system), but we saw a shift previous to that of about $60 \%$ of our food was marketed through food service or restaurants and $40 \%$ through retail. We saw a shift to about $100 \%$ needing to be serviced through the retail industry, so that brought to bear a lot of challenges. Much of the packaging that goes into food service or restaurant is larger quantities. It also doesn't have to have ingredient labeling to the same extent and nutrition information to the same extent that retail packaging has to have. So we had to work with the food manufacturers as well as a lot of the food distributors to try to move that food out of the Peglers, the Syscos, the US Foods ${ }^{6}$ of the world, and to the K rogers ${ }^{7}$ of the world so they could get that food out. A nd many times, that meant we needed to relax some of our regulatory requirements for labeling, also some packaging as we wanted to be able to take both boxes of bacon, if you will, and be able to have a deli repackage them to be able to sell through the deli window and to be able to get the food that was destined for that food service to be able to be usable in retail. We also had to adjust milk marketing orders because milk that needed to be bottled then or put in gallon jugs was destined, under those marketing orders, for cheese production because there's more cheese demand in the restaurant industry, and so we shifted some of those to be able to address some of those immediate shortages.

We also saw some collapse in the marketplace on the $\mathrm{CME},{ }^{8}$ especially as we saw people that participate in that market, in those exchanges, become concerned about what the future was. And so

6. These providers (Pegler, Sysco, and US Foods) are business-to-business food services that provide food to restaurants, healthcare facilities, and other commercial establishments. See The Sysco Story, SY sco, https://www.sysco.com/A bout/C ompanyProfile/The-Sysco-Story.html [https://perma.cc/7B 4C-A 86A ]; A bout US Foods, US Foods, https://www.usfoods.com/about-us-foods.html [https://perma.cc/FB 4U B 9A R ].

7. Kroger is one of the largest grocery retailers in the U nited States. See O ur Business and Operations, KROGER, https://www.thekrogerco.com/about-kroger/ourbusiness/ [https://perma.cc/3C 8Q - H Y J 7].

8. CME stands for the Chicago Mercantile Exchange, a commodities exchange that reports closing prices and trading activity for cheese, butter, and nonfat dry milk. See Chicago M ercantile Exchange - Cash D airy Markets, U .S. DEPT. A GRIC., https:// www.ams.usda.gov/market-news/chicago-mercantile-exchange-cash-dairy-markets [https://perma.cc/E X W 8-4H 2N ]. 
USDA, especially my group, had to have some conversations with $\mathrm{CFTC}^{9}$ and CME to make sure that we had the appropriate stops in place and that we could control the market so that it didn't react in a way that caused too much damage. Fortunately, we did not have to put in special measures-the normal protocols were able to handle and react to the market conditions appropriately. B ut it did cause a lot of stress, especially in the production industry, as we saw some of those prices for hogs and live cattle face some serious deterioration.

A s a result of COVID and people stepping away from their jobsmany of them not salaried and not able to work from home, losing their jobs-we saw that they also lost their buying power at the grocery store, so that was a challenge that had to be addressed. We also saw schools closed, and many children got not only their lunch at school but many of them got breakfast at school. A nd many children in many communities across the $U$ nited States also take home "buddy packs" or some type of food for the weekend as well. A nd so U SD A had to react to be able to address those needs as well. Luckily, because of trade mitigation that we had in place before, we were buying a lot of food, and so the stockpiles were fairly high in most of the food banks. We also had section 32 purchases, which are purchases that USDA makes in relation to low market prices or adverse marketing conditions of certain products, and so those stocks were higher. A nd then we also, last fall, had significant peanut forfeitures that we bartered some of that food and increased our supply of peanut butter, which is a very nutritious product and kind of a catch-all and especially popular at food banks for families that may not have mom and dad at home all day long, the kids can always make a peanut butter sandwich if they need to and aren't allergic to it.

A gain, we had to make regulatory adjustments to our feeding programs. So, our food nutrition services had to relax some of the TEFA $\mathrm{P}^{10}$ regulations as far as income requirements. A Iso, we shifted greater authority to states to be able to move food around and be able to put money on credit cards, E BT ${ }^{11}$ cards, for clients to be able to use

9. CFTC stands for the Commodity Futures Trading Commission, which regulates the commodities futures and derivatives market. See The Commission, Com MODITY FUTURES TRADING COMm'N, https://cftc.gov/A bout/A boutTheCommission [https://perma.cc/H 5BE-34L Q ].

10. TEFA P stands for The E mergency Food A ssistance Program, which provides low-income individuals and households with surplus commodities that the U SD A donates. See TE FA P Fact Sheet: What Is the E mergency Food A ssistance Program, U .S. DEPT. A GRIC., https://www.fns.usda.gov/tefap/tefap-fact-sheet [https://perma.cc/ 4V 2T-H W M 8].

11. EBT stands for Electronic B enefits Transfer, an "electronic system that allows a Supplemental Nutrition A ssistance Program (SNAP) participant to pay for food using SNAP benefits." What Is Electronic Benefits Transfer (ETB)?, U.S. DEPT. A gric.: Food \& Nutrition SERvice, https://www.fns.usda.gov/snap/ebt [https:// perma.cc/2NFC-TTTV ]. A participant can debit their SNA P E BT account when shopping at authorized retail stores to reimburse the store for the food they purchased. Id. 
in the retail industry. We also launched a very aggressive feeding program, the Farmers to Families Food B ox program ${ }^{12}$ that many of you have probably heard about. We will have distributed, by the end of 0 ctober, $\$ 4$ billion worth of food through that program. It was designed at a time in A pril where farmers were having to destroy crops in the field, especially fruit and vegetable farmers that had crops maturing at that time, because the food service industry, their market, had gone away. They weren't able to adapt rapidly to getting that into retail. A the same time, we saw milk being wasted on the farm because of the processing lag and the adjustment in there. A nd so we really use that $F$ armers to Families initially as a relief valve for farmers as well. A nd so we asked farmers to team up with the distributors that were letting people go, because they weren't able to distribute to restaurant and food services agencies, to figure out a way to take that food from the farm, box it up in fruit and vegetable boxes, dairy boxes, milk boxes, and meat boxes to be able to feed families. A nd as of last week, we had distributed over seventy-five-million boxes of food that were coming close to $\$ 2.5$ or $\$ 2.6$ billion worth of food. We are going to continue that program into the near future to be able to continue to address those needs that are out there in the industry. A nd now we've seen the farm and distribution system has been able to adapt to COVID, but families are still hungry. So we're shifting the box program to focus more on a combination box that will provide complete nutrition to families and a little bit away from that farmer, and the immediate need we saw in A pril isn't there. Farmers will still benefit from food going to families, but we're focusing our delivery system in a way that we think will benefit families and work for food banks and community organizations trying to provide that relief.

The third thing I said we were going to talk about a little bit is the food-processing crisis. A s we saw, some of the outbreaks start to develop in the populations that are employees at our food processing centers, as well as just the fear of infections start driving absenteeism, as well as absenteeism because people were sick. We saw a few other problems develop: N ot only were the employees not able to come to work, or chose not to come to work, but we saw capacity at those slaughter facilities reduced. We also saw state health departments start engaging with the packing industry to try to help them adjust to COVID and prevent illnesses, many times in a way that didn't necessarily follow $\mathrm{CDC}^{13}$ guidance or guidance coming out of USDA or

12. USDA Farmers to Families Food Box, U.S. DEPT. A gRIC.: A gRICULTURAL MARKETING SERVICE, https://www.ams.usda.gov/selling-food-to-usda/farmers-to-families-food-box [https://perma.cc/X 79F-X Q E 7].

13. $C D C$ stands for the Centers for $D$ isease Control and Prevention, the $U$ nited States' health protection agency. A bout CDC 24-7, CENTERS FOR DISEASE CONTROL AND PREVENTION, https://www.cdc.gov/about/default.htm, [https://perma.cc/2NM 3FT36]. 
OSHA.${ }^{14}$ We also saw activities by local health departments. So not only were packing plants having to deal with the state health department, they might have a local health department that was setting up expectations on them. A nd so, in A pril, OSHA, USDA, and CDC worked together to come out with guidance that was supposed to kind of set the standard for what a national guidance should be for those food processing industries that we felt were essential to feeding A merica. The President followed up with an executive order that pointed to that guidance on A pril 26 as the law of the land, if you will, as far as how states and local health departments should measure processing industries. A nd so slowly we eliminated the problems that were expectations where we had local health departments asking plants to shut down-we eliminated that problem and were able to just deal with the health concerns, or the reduction because of health, or the reduction because of absenteeism. A s a result of that reduction of slaughter, USD A had to deal with and provide some aid and guidance to the food-animal industry to deal with the backlog of swine that weren't being killed or beef animals that weren't being slaughtered.

A nd so in the swine industry, there became a lot of concerns about, "D o we need to euthanize animals?" Because, in the swine industry, once animals reach a certain point, they're not able to really go through the slaughter facility once they become too heavy. The beef industry has better mechanisms to handle added weight and differing weights of animals. The pork industry is really engaged more to a certain size of animal. We worked with the industry to understand what depopulation might look like and how we would have programs to address that. U nfortunately, all the indemnification programs that Congress has authorized U SD A to carry out have to do with depopulation because of a disease outbreak or a disease concern. We don't have authority to provide indemnification because of a collapse of a slaughter industry, and so that became a challenge. Luckily, a lot of that concern, especially in the swine industry, we were able to get plants to regain capacity, producers tried to figure out how to stall some of those growth curves in those swine, as well as deal with some of the birth rates as well. A nd so we didn't see the seven million hogs we thought at one time might have to be euthanized-that never came to fruition. The beef industry was able to adjust their rations, they could slow down gain better in those animals than the pork industry could. W ith a less concentrated industry-with a less confined focus

14. OSHA stands for the O ccupational Safety and $\mathrm{H}$ ealth A dministration, which ensures "safe and healthful working conditions for working men and women by setting and enforcing standards and by providing training, outreach, education, and assistance." A bout OSHA, U.S. Dept. Labor: Occupational Safety \& Health A DMINISTRATION, https://www.osha.gov/aboutosha [https://perma.cc/55N U -7Q S9]. 
on the beef industry-we're able to keep animals on pastures or in backgrounding stages for longer, and so that helped a lot.

B ut with that, it's still - with all those measures that we had put in to try to address food processing, feeding programs- we still had a need for implementation of aid packages. A nd the first one of those was announced on A pril 17, when the President asked U SD A to mobilize some dollars that we had in $\mathrm{CCC}^{15}$ funds to be able to provide the first CFA P ${ }^{16}$ payments. Congress then passed the Families $\mathrm{First}^{17}$ and the CARES A ct ${ }^{18}$ that provided additional monies that put more deposit into our CCC accounts in July. A nd so we devised a program here at USDA, with the support of the President, to be able to make payments to farmers in, what we deemed, those industries and during the time period that we can measure losses. A nd so the fruit and vegetable industry got payments based on their losses that we calculated based on some of the numbers that we had available to us at U SDA. We also went through a NOFA ${ }^{19}$ process that allowed those specialty crop growers to provide us with documentation, and as a result of that, we've added over sixty different specialty crops and commodities to that list of eligible recipients.

W e were able to make payments to beef and pork producers, as well as dairy producers, as a result of that. We also had a formula that we put in place to reimburse some row-crop producers for their crops' losses during that time frame of the first quarter. We're now working on a second CFA P payment that will go beyond that first quarter and look at losses that agriculture has sustained as a result of the continued changes in the marketplace and the continued deterioration of prices over the summer. A nd we are going to finish up on the sign-up for the first CFA P on September 11, coming up tomorrow. A nd then we can look forward to the announcement of how we are going to roll out a subsequent CFA P payment. Then Congress, if they decide to do an additional COVID payment for agriculture, U SDA stands ready to implement "CFA P three" if necessary.

15. CCC stands for Commodity Credit Corporation, a wholly owned government corporation used to implement specific programs from Congress. See Commodity Credit Corporation, U.S. DEPT. A GRIC., https://www.usda.gov/ccc [https://perma.cc/ 89V F-E HUB ].

16. CFA P stands for Coronavirus Food A ssistance Program, which provided financial assistance to agricultural producers whose operations were impacted by COVID -19. See Coronavirus F ood A ssistance Program - A dditional A ssistance, https:/ /www.farmers.gov/cfap [https://perma.cc/X 4W 7-PM H D ].

17. Families First Coronavirus R esponse A ct, Pub. L. No. 116-127, 134 Stat. 178.

18. Coronavirus A id, R elief, and E conomic Security A ct, Pub. L. No. 116-136, 134 Stat. 281.

19. NOFA stands for a "N otice of Funding A vailability." See, e.g., N otice of Funding A vailability; Coronavirus Food Assistance Program (CFAP), DEPT. A grIC., https://www.farmers.gov/sites/default/files/documents/CFA P\% 20N OFA .pdf [https:// perma.cc/96P Q -3d9W ]. 
A nd then finally, maybe, to wrap up my general comments and then be ready for some question and answers, we see some continuing ramifications as a result of COVID-19. International trade continues to have some disruptions as different countries have concerns about food safety and whether or not COVID processed in a plant that had employees that were suffering from COVID or had subclinical COVID - whether or not that meat or poultry product is dangerous. We have pretty exhaustive science to show that COVID is not a foodsafety issue, but we've had to deal with those talks and negotiations with some of our trading partners as we've gone through that process.

W orker-safety concerns continue to be very much top-of-mind as well. USDA, as we talked about before, worked with OSHA and CDC to come out with guidance. But we continue to need to tweak that guidance and the application of that guidance as CDC comes out with new protocols or new ways of dealing with COVID to protect employees. A nd so, we very much continue to work with OSHA. In many cases, especially in processing facilities, we need to talk about what, not checking every box or every precautionary step that could be taken, but what is the most of the best, or how do we apply those techniques to the circumstances that are at hand in those packing facilities.

Feeding programs continue to be an issue, especially as the CA RES A ct expires and the unemployment benefits have been readjusted as a result of the expiration of that period. W ith trade mitigation, that extra food that we're buying will come to an end at the end of this calendar year. The boost that we got through Families First and CARES, that investment from Congress will come to an end at the end of $O$ ctober, so we could see some continuing need outstrap our ability to continue to supply food with the monies made available from Congress as we round out the year. We also are taking a look at lessons learned, and what's the hot wash of our experiences, and how we, here at USDA, can be prepared if we face another round of COVID or another human health concern in the future. We want to make sure we've taken adequate notes, and learned lessons, and adjust our regulatory programs in ways that might help us be more nimble and be able to react quicker to those.

A gain, every situation that we face is unique. It's unique to figure out how to deal with states and different perspectives, different infection rates, but we continue to try to be able to adapt to that. A nd with that, maybe I would be ready to address some questions. A nd I'm not sure, I forgot to ask you how we were going to handle that, but I look forward to the questions.

PROFESSOR BRADBURY: I'm going to help you out there, I'II let you catch your breath there just a minute, but we do have several questions. But one, thank you very much for that run-down. I'm in 
private practice and do a lot of work in agriculture, and it's interesting to hear you talk about the USD A end of that, because I've had producers and associations go through all of this process, and boy it isit's been an impossible time, but really great response. If you think, we've really just been at this since $M$ arch, a tremendous response from USDA as well as the states to sort these things out.

O ne question I want to ask - and then I've got several questions in the queue for you- is you mentioned lessons learned, but so much of our regulatory system has sort of been on the presumption of all things normal. A nd we learned this year in agriculture that, boy, you can have a major black-swan event like this. A nd we've adapted on the fly; we went through the phase where plants were shutting down from processing meat, to milk and commodities going literally to waste. What are you all looking at going ahead? A nd hopefully it's not another COVID, but it could be another significant disruption to agriculture. Learning what we've learned, how might we change our policy making process?

MR. IBACH: Well, I think that there are some options for us to look at. M ilk-marketing orders have served a purpose over the years to be able to level out supply and make sure that we have dairy available across the U nited States. But they also have directed products in certain supply chains. A nd so, I think that the fact that we had to adjust rapidly to be able to redirect milk to those supply chains might give us an opportunity to work with the industry to help understand whether or not we need to provide more flexibility for milk to run freely to demand on its own without U SD A having to make that decision would be one lesson learned.

The other lesson learned is, as we saw, the importance of the foodservice restaurant industry and the packaging that went around to that. How can we work with food processing to be more nimble about changing their ability to move to different sizes of packaging? Y ou don't need a twenty-pound sack of cheese, you need a three pound sack of cheese if you move from food service to retail. A nd so how can we help them adjust to that? Same way with consumers buy steaks, they don't buy a wholesale cut of rib. So how do we help put that nimbleness in place and work with the industry?

PR OFESSOR BRA D BURY: Good, well, let me turn to some questions. I've got quite a number of questions from the audience here, let me pose some of these to you. First off, you mentioned certain restrictions were loosened on distribution and food packaging, nutrition information. B ut first question: Have these been reinstated? If they're not reinstated, is there a time frame for that? A nd then I'll just fold in the last piece of this: D o you see this making a long-term impact to how these labeling and requirements may be interpreted? 
M R . IB A CH : So the labeling and nutrition information are very important components. Those were only relaxed for a brief period of time-I think for a country-of-origin labeling on produce that needed to move out of food service and restaurant into retail, that was only for thirty days, and that expired. So we are back to normal on all of our expectations for food labeling and package labeling. That was only temporary to address that "shift in user" that needed to occur.

PROFESSOR BRADBURY : A II right, well, good. Question. Y ou mentioned many of these food-to-family programs and distributions were expanded because of the pandemic. Do you feel that this illumination of the bigger issue of food insecurity that's out there will spur some legislative or regulatory policy making for greater funding in this program?

M R . IBA CH: N utrition programs and feeding programs in the past had really focused on shelf-stable products-dried beans, peanut butter, rice, dried potatoes, canned fruits and vegetables-and a little bit on frozen, but not very much, because most food banks didn't have refrigeration and freezer capacity to handle large volumes. But as we needed to move some of that fresh produce and fresh meats into the food supply, we've really seen the people that were clients of those food banks embrace that fresh product and the higher quality- what their perception of higher quality food and better nutrition-access was. A nd so I think long-term, we will see demand for more fresh product going through the food bank systems.

W e've also seen expansion through the trade mitigation of freezer and refrigeration capacity within that food bank system, and so I think that will continue to grow.

I think we're also going to see Congress look at adjustments, whether it's making programs like the Farmers to Families Food B ox program more permanent, or an outgrowth of that, a permanent program, or whether it's expansion of SNA P benefits to be able to allow people to go grocery shopping on their own more and take less pressure off the food banks. I think that's an outgrowth that we could see as well.

PROFESSOR BRADBURY : J ust an observation from my standpoint, that program was so good-not only in supplying food to those who need it, but in the early phases where we had the food service disruption and restaurants shut off, and so much agriculture was on the front page, but not in the best light, that was being covered pretty heavily-didn't appear good, but that program, when you all put that together, really solved two problems. One, it provided food to those who needed it but also diverted those crops such that they're not being wasted because that was just a little hard to bear. 
MR . IBA CH : So the beauty of that program also was that that was about thirty days from concept to delivery of the first box. In the federal government, that should have been an eighteen- to twenty-fourmonth process to get a program up and running like that. So the fact that A MS was able to devise and come up with a program and get it out that fast was unbelievable. We had a few participants that are contractors that were questioned, but for the most part, every contractor delivered about $90 \%$ of what they were contracted to do. We only paid based on deliveries, so U SDA didn't lose any money from anybody that wasn't to deliver, and we only had two contractors fall completely out of the program.

PROFESSOR BRADBURY: Well, that's great. A nd it put agriculture in the right light.

MR . IBACH: Y eah.

PROFESSOR BRADBURY: OK, good question. As you know, we've got some lawyers on here and some law students. So here's one I think is a good question: What are the biggest tensions and obstacles and/or sticking points between the states and the federal government? Of course you're USDA, but so much of this has to be done in relationship with the fifty states. Can you, I don't know, tell some stories or comment on that?

MR. IBA CH: Well, I think different states have different philosophies based on their political composition of how they want to roll out feeding programs. Some states want to just be able to make everybody eligible that walks up to a food distribution program. A nd some states very much want to be need-based and want to have some kind of a verification that the client is in need of food. So U SD A trying to balance that, as well as trying to balance the voices in Congress that represent those two different philosophies, is definitely a challenge all the time in feeding programs. Y ou see that struggle in the debate about those feeding programs. That's something that we still feel is important-that we service the most needy with the most food-and we figure out how to devise programs that aren't abused and don't have fraud in them, as well.

$\mathrm{B}$ ut the Families to Food B ox program did not have verification. It was meant to meet the immediate need. B ecause we had people that had great jobs that went away overnight that found themselves in need of food. A nd we didn't have the capacity, through the food banks, to be able to provide verification, and states didn't have the capacity to provide income verification during that immediate crisis. N ow that we're getting ourselves back up on our feet, I think we'll be able to address those issues and concerns. 
PROFESSOR BRADBURY: Good, good. Here's another one, probably you and your staff have had discussions along these lines, but the question is: In dealing with these major events, such as COVID, how does USDA balance the need to get information out quickly that is in-depth with the need to have accurate information out there? So it's sort of the speed versus accuracy, and obviously you want both, but how do you do that?

M R . IBA CH: Y eah, and I think we're seeing this debate take place in the media, right, today about that we may know some things or be hearing some things, but what's our responsibility to try to keep people reacting with a calm and level head and not overreact? When we were having the pork industry reach out and say, "W e're going to have to euthanize seven or eight million hogs here in the next few months," we needed to react calmly and try to devise a program behind the scenes that was going to be able to enable us to help the industry if that was needed. But we also needed to devise a program to make sure that we weren't going to have to destroy food in that manner. That is the balance that whenever leading a state agency or a federal agency, you have to figure out how to prepare for the worst while trying to assure society that that worst case scenario isn't going to occur.

PROFESSOR BRA DBURY: A nother question for you. Y ou mentioned that you'll be evaluating lessons learned in the agency as well as you personally. But at this point, what is one lesson that you gathered as a farmer and policymaker about the response to the COVID here that revealed something about our food system that we really do need to adjust?

MR . IBACH: Well, definitely the nimbleness of our food production system to go from $60 \%$ food service and restaurant use to $100 \%$ retail demand and distribution, basically, was something that we really weren't prepared for as a food industry. A nd the distribution system wasn't prepared to do that. I don't know that we can ever have it completely nimble enough to make a switch over in a matter of days, or weeks even, in the future, but maybe we can be a little bit more aware of what regulatory reforms or relaxation that we need to put in place to do that.

I also think that one of the lessons learned is the need to have states and local municipalities understand critical infrastructure, critical jobs, and critical employees that need to show up for work to be able to make sure we can supply food to people across our nation.

A nd one of the biggest challenges was local health officials that are worried about public health were really focused on eliminating virus risk or the risk of people getting COVID. That doesn't line up with 
the need to have people show up for work, harvest animals, and get that food in a form that consumers can actually consume.

PR OFESSOR BRADBURY : From my experience, watching it unfold in Texas where you had shelter-in-place restrictions and counties and cities setting these-it was a big deal when Homeland Security identified agriculture as a critical industry such that they were incorporated. B ecause literally, things about getting employees to work and having them authorized to get to work at that time was really difficult. B ut I think this was a time that sort of demonstrated to the greater public and local municipal officials how important agriculture is.

MR . IBA CH: Y eah, that's for sure.

PR OFESSOR BRA DBURY : O ne other final thing as we round the bend here, I'm a proud former intern of FA $S^{20}$ downstairs and I'm just curious, you mentioned briefly international trade, but what are the pushes and the pulls there? I know other countries are concerned about infections, and many countries have kind of turned inward at this risk here, but what do you see in terms of marketing our ag commodities internationally in the year ahead?

M R . IBA CH: W ell, the U nited States has always been a strong proponent of science-based trade and of sanitary regulations being in place that are based on science and not having phytosanitary precautions put in place that are based on a precautionary principle. I think that's important, as we learn lessons from COVID, that we need to continue to work with the world to base trade on science so that food can move where it needs to move around the world. We know that certain countries, A merica, the U nited States, is a food-producing country. A nd the world relies on us being able to ship food around the world to be able to balance nutrition around the world. We can't let a pandemic interrupt that food distribution system worldwide.

PROFESSOR BRADBURY : Right. Right. Well, I mean last area, because you mentioned it at the beginning of your remarks. B ut I'm curious, with your son back in Nebraska and your roots there, I'm certain you're hearing from old friends and other farmers and industry folks back in N ebraska. What are you hearing from them on the other end of this spectrum?

MR. IBACH: Y eah, farmers and ranchers are eternal optimists. They still continue to believe that they're going to be needed and

20. FA S is the acronym for the Foreign A gricultural Service, a department within the USDA. See Foreign A gricultural Service, U.S. DEPT. AgRIC., https:// www.fas.usda.gov/ [https://perma.cc/] 7U 6-FR K 4]. 
there's better days ahead to produce and sell food. I think that the trade-mitigation monies that the President has authorized, the COVID payments that the President authorized and Congress supported extending, have been important to producers around the U nited States in being able to pay the bills. A nd I think we've stemmed bankruptcies, and we've been able to keep families on the farm across A merica. H opefully as we get better trade agreements in place and continue to increase export markets, as well as level out the food-demand system here in the U nited States, we'll see better prices return and reward those farmers for hanging in there.

PROFESSOR BRADBURY : I think that's all the questions we've got, but just a few things. I hope you're finding time to get an adequate amount of sleep with everything that you're covering in that job. A nd one, thank you for leaving N ebraska to do that for all of us.

MR. IBACH: It was a little bit rough during A pril. We started working early in the morning, and there were still conference calls going on at ten o'clock at night. But...

PROFESSOR BRADBURY: Oh I'm sure.

M R . IBA CH : W e're getting things handled now and getting back to normal.

PR OFESSOR BRA DBURY : Smoother water. Then mostly, on behalf of T exas $A \& \& M$ L aw School as well as D rake $L$ aw School and their ag program, we really do appreciate you and your staff making time so that you could join us today to talk to [us]. I think this is our sixth or seventh year of having this symposium, so it's great to have an undersecretary join us for this.

M R. IB A CH: W ell, it's been my pleasure. Thank you for asking me.

PROFESSOR BRA DBURY: Well, you bet. I'm sure there's a line of people waiting to talk to you outside your door, so we'll let you go. Thank you very much, and have a good afternoon.

MR . IBA CH: Okay, thank you.

PROFESSOR BRADBURY: Bye-bye. 
